\title{
Design and experiment of spray and rotary tillage combined disinfection machine for soil
}

\author{
Jinwu Wang, Wenpan Yang, Xiaobo Sun, Xiang Li, Han Tang* \\ (College of Engineering, Northeast Agricultural University, Harbin 150030, China)
}

\begin{abstract}
A spray and rotary tillage combined disinfection machine for soil was designed to solve the serious problems of plant diseases and insect pests, and it was divided into two operations which were soil disinfection and rotary tillage. The main structure and working principle of this machine were illustrated and analyzed. The reasonable structural parameters of the key parts of this machine were optimized, such as spraying disinfection system and rotary tillage land preparation system. To optimize the working performance and obtain better operation parameters, the orthogonal experiments were carried out to analyze the influences of three factors (forward speed of driving machine, rotational speed of rotary tillage, and working pressure) on the working performance. The mixing uniformity coefficient and the variation coefficient of spraying were selected for evaluating working performance. The range analysis and variance analysis were studied based on experimental data. The results showed that, the mixing uniformity coefficient of spraying was $93.95 \%$ and the variation coefficient was $6.01 \%$ with a working speed of $3 \mathrm{~km} / \mathrm{h}$, rotational speed of $2000 \mathrm{r} / \mathrm{min}$ and working pressure of $2.0 \mathrm{MPa}$. The machine can meet the agronomic requirements of disinfection and plowing, which was designed simply, compactly and strong applicability. The results can provide a guidance and technical support for preventing the plant diseases and insect pests, developing sustainable and ecological agriculture and improving the efficiency of compound cultivation.
\end{abstract}

Keywords: agricultural machine, soil disinfection, spray, rotary tillage, compound operation

DOI: $10.25165 /$ j.ijabe.20191201.3640

Citation: Wang J W, Yang W P, Sun X B, Li X, Tang H. Design and experiment of spray and rotary tillage combined disinfection machine for soil. Int J Agric \& Biol Eng, 2019; 12(1): 52-58.

\section{Introduction}

In recent years, with the development of planting pattern in continuous cropping of high value-added crops, the specialization, institutionalization and scale of crop production continue to increase $^{[1,2]}$. However, it has caused a serious pollution and insects pests in soil, which has become the main problem that affects the crop yield and quality. Soil disinfection is an advanced technology to kill fungus, bacterium, nematode, weed, soil borne virus disease, insects underground and rodents with high efficiency $^{[3]}$. The methods of soil disinfection mainly include physical disinfection, chemical disinfection and biological fumigating disinfection. The technology and related machines attached for physical disinfection with the advantages of convenience, high efficiency and low cost, which is a key point in research around the world ${ }^{[4]}$. Many scholars have conducted researches on the development of physical disinfection for soil ${ }^{[5-7]}$. The combination of mechanical and electrical technologies can be carried out through high-temperature flame, high-pressure steam

\section{Received date: 2017-07-13 Accepted date: 2018-11-10}

Biographies: Jinwu Wang, Professor, research interests: farm machine and mechanical reliability, Email: jinwuw@163.com; Wenpan Yang, Master, research interest: agricultural mechanization engineering, Email: 1543855743@qq.com; Xiaobo Sun, Master, research interest: agricultural mechanization engineering, Email: 735863479@qq.com; Xiang Li, Master, research interest: agricultural mechanization engineering, Email: 646425886@ qq.com.

*Corresponding author: Han Tang, $\mathrm{PhD}$, Lecturer, research interests: agricultural mechanization engineering and precision planting technology. College of Engineering, Northeast Agricultural University, No.600, Changjiang Road, Xiangfang District, Harbin 150030, China. Tel: +86-451-55191188, Email: tanghan19910102@163.com. and burying capsule. However, these soil disinfection technologies only apply to small greenhouse, and it cannot be expanded and applied in field crops for its low-severity, high-priced, diversity of disinfectant, uncertain ways of operating, tense time of busy season and lacking awareness of disinfection. Researches about disinfection have been at the primary stage in China ${ }^{[8,9]}$. Many operations are in the way of mulching after spraying disinfectant, which can cause environmental pollution and impact on the following operation for tillage and soil preparation $^{[10]}$.

In this case, in order to solve the problems of plant diseases and insect pests, a rotary tillage and combined disinfection machine for soil was designed. The operation mode combined spraying microbial disinfectant with the plowing technology. The working principle and the optimized structure parameters of key parts were analyzed in this paper. The field orthogonal experiments were conducted to obtain better operation parameters. This study can provide a guidance and direction for the research of disinfection machine and its key component, and then promote the development of green and efficient production pattern of soil.

\section{Overall structure and working principle}

\subsection{Design principle}

Soil disinfection technology mainly solves issues which are caused by continuous cropping pattern of high value-added crops. Researches about soil disinfection were mostly applied to the greenhouse at present, and there were no standard and perfect agronomic requirements related to soil disinfection in field crops. The research carried out in this paper should consider the agronomic requirements of spraying microbial disinfectant as follows: 
1) The diluted solution is sprayed to the surface of soil or watered into soil directly, so that the liquid would irrigate into deep soil (150-200 mm in depth) to kill germs. It applied to operate in greenhouse, sheds or field crops.

2) The liquidity of disinfectant is conductive to contact between soil and liquid ${ }^{[11]}$. The liquid should make sure not to burn crop seeds. If the liquid is too little, the effect of disinfection would not be achieved. If liquid is too much, it will delay the subsequent planting time.

3) Selection of suitable microbial soil disinfectant can avoid additional coating operation after spraying conventional pesticide disinfectant, and reduce a secondary pollution.

4) The ideal operating time is before planting in spring or after harvesting in autumn.

\subsection{Main structure}

As shown in Figure 1, the spray and rotary tillage combined disinfection machine mainly consisted of rotary tillage system (rotary blade, rotary cutter shaft and soil covering shell), spraying disinfection system (disinfectant spray sprinkler, hanging pole, liquid medicine box, disinfectant pump and fixed frame), belt wheel transmission system, main frame and three-point hitch linkage, etc. The disinfection spray assembly should match the dimensions and structural parameters of rotary tillage system. Moreover, combined with the characteristic of liquid medicine, the design and selection of spraying disinfection system were carried out. The transmission form of machine was the main drive in double axis. Spraying disinfection system and rotary tillage system were formed as one body. The rotary tillage system was composed of fifty IT245 rotary blades which were arranged interlaced internally and externally in double helix to improve rotary tillage quality and reduce power consumption ${ }^{[12]}$. Nine large spray sprinklers were arranged evenly under the hanging pole, which made spraying take place at the time of rotary tillage and reduce the influence of external factors on spraying operations. The pressure adjustable diaphragm pump was selected as the disinfectant pump medicine, and it can be controlled by adjusting the liquid pump pressure valve to control the flow rate in unit time. The belt wheel transfers the power of gearbox to disinfectant pump to drive spraying. Medicine boxes were fixed on two sides of the fixed frame, which improved the stability and balance.
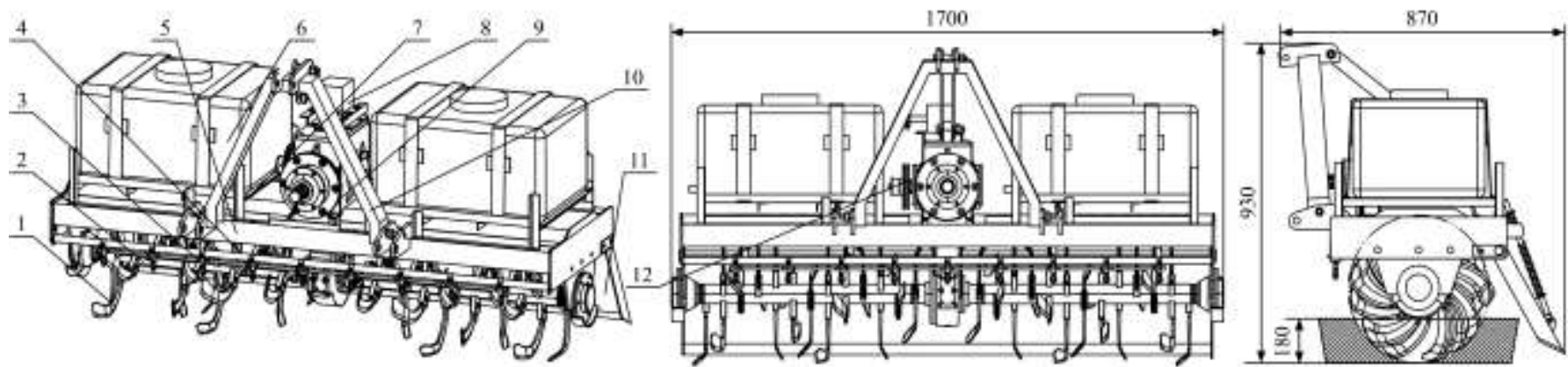

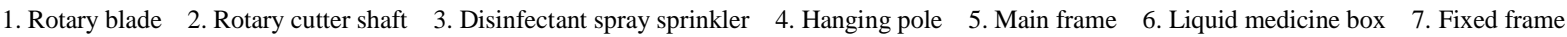

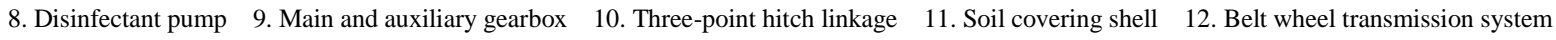
Figure 1 Spray and rotary tillage combined disinfection machine for soil

\subsection{Working principle}

The working process of combined disinfection machine was mainly divided into two sections, namely spraying disinfection and rotary tillage. The combined disinfection machine was hung on the driving machine through three-point hitch linkage. The proper depth can be controlled by adjusting the length and angle of the pole. According to the internal state of soil and the characteristics of disinfectant, the mixture ratio was adjusted and dissolved evenly in the liquid medicine box. The power of spraying disinfection and rotary tillage came from the power output of tractor, and transmitted to disinfectant pump and rotary cutter shaft through various universal couplings and gearboxes. In the actual operating process, microbial disinfectant was sprayed evenly on the soil surface by spray sprinklers, and rotary tillage system makes the disinfection contact different layers of soil sufficiently.

\subsection{Technical parameters}

The disinfection machine combines with spraying disinfection and rotary tillage to solve the problem of two conventional operations of soil tillage and disinfection. The operation process met technical requirements of disinfection and plowing, made the disinfection contact different layers of soil sufficiently, and carried out the compound operation. In actual operation, the microbial disinfectant was chosen as the liquid medicine, which had little pollution and was harmless to beneficial organisms. It could maintain ecological balance and could be applied to field crops disinfection. The whole configuration adopted a lightweight design which had simple construction and high reliability. The main technical parameters of disinfection machine are shown in Table 1.

Table 1 Main technical parameters

\begin{tabular}{lc}
\hline \multicolumn{1}{c}{ Items } & Parameters \\
\hline Boundary dimensions/mm & $1700 \times 870 \times 930$ \\
Mass/kg & 470 \\
Mating power/kW & 50 \\
Forward speed $/ \mathrm{km} \cdot \mathrm{h}^{-1}$ & $3-6$ \\
Operation width/mm & 1600 \\
Operation depth/mm & $150-180$ \\
Capacity of medicine box/L & 250 \\
Pump type & MB345/2.5 \\
Rotary blades arrangement & Double helix \\
Rotary blade type & IT245 \\
Rotational speed/r.min ${ }^{-1}$ & $300-650$ \\
Spray sprinkler spacing/mm & 170 \\
Quantity of spray sprinklers & 9 \\
\hline
\end{tabular}

\section{Main structure design}

The configurations of spraying disinfection system and rotary tillage system directly affected the quality of whole complicated compound operation. This study focused on the optimal design of critical parts to improve disinfection quality and rotary uniformity and to meet the agronomic requirements. 


\subsection{Spraying disinfection system}

\subsubsection{Disinfectant spray sprinkler}

In actual operation, disinfectant was sprayed evenly on the soil surface by special spray sprinkler, and then rotary tillage system made the disinfection contact different layers of soil sufficiently, as shown in Figure 2. The type, quantity and configuration of spray sprinkler directly affected the spraying quality.

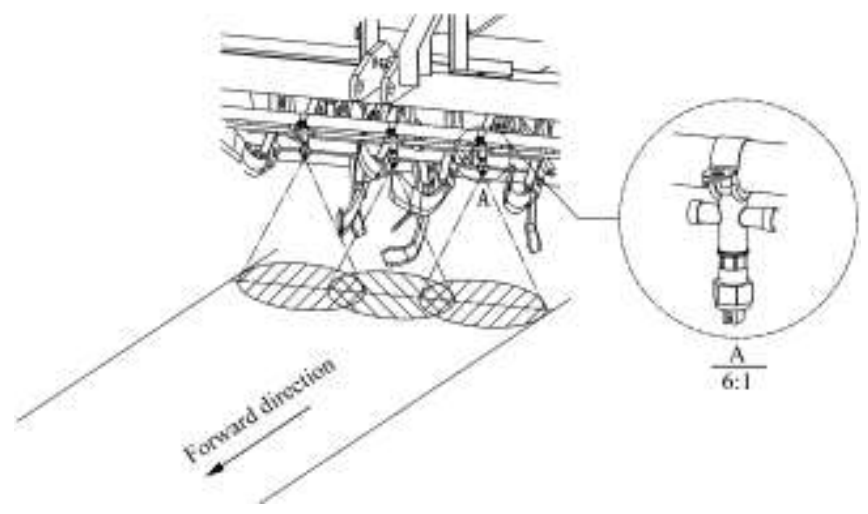

Figure 2 Structure diagram of compound operation

A conical atomization sprinkler was chosen as execution component to make the structure compact ${ }^{[13,14]}$. The flow range was $0.3-1.2 \mathrm{~m}^{3} / \mathrm{h}$ under standard conditions, and it would generate solid conical deposits. In order to guarantee the disinfectant sprayed into the soil would be stirred adequately and to reduce the waste of disinfectant, the operation width $(1600 \mathrm{~mm})$ of spraying disinfection system should be the same as that of rotary tillage system. At the same time, the sprinklers should be close to the ground as possible to prevent the drift phenomenon caused by wind under the circumstances that the rolled clod cannot block sprinklers. Figure 3 shows the configuration of simplified spraying disinfection system under the actual condition. Considering the flow requirement of single sprinkler and the overlapping rate of adjacent spraying range, the configuration of spray sprinklers was designed as follows:

$$
a=\frac{L_{z}-D b}{D-D b}
$$

where, $a$ is the quantity of spray sprinklers; $D$ is the spraying range of single sprinkler, $\mathrm{mm} ; b$ is the overlapping rate of adjacent spraying range, $\% ; L_{\mathrm{z}}$ is the whole operation width, $\mathrm{mm}$.

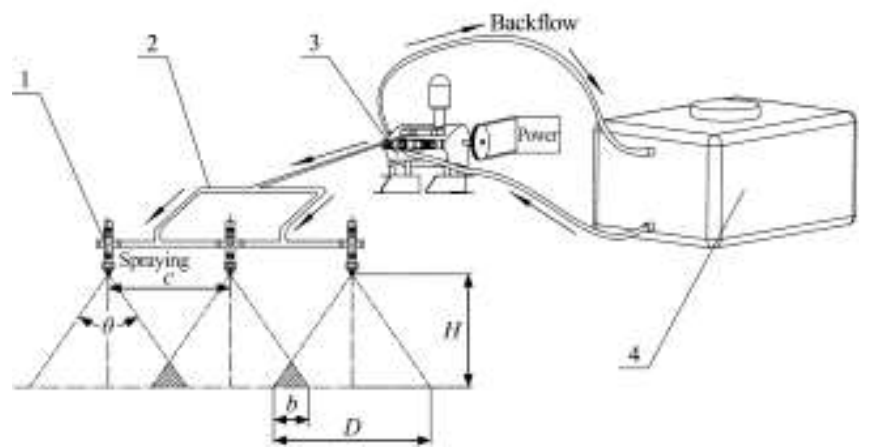

1. Disinfectant spray sprinkler 2. Spray line 3. Disinfectant pump 4. Liquid medicine box

Figure 3 Configuration of spraying disinfection system

By analyzing the consumption of microbial disinfectant and the fixed operation width, the overlapping rate of adjacent spraying range was $b=29 \%$, the spraying range of single sprinkler was $D=240 \mathrm{~mm}$, the spraying angle of single sprinkler was $\theta=44^{\circ}$.
The parameters were calculated by Equation (1), and the quantity of spray sprinklers was $a=9$ and the spacing was $c=170 \mathrm{~mm}$.

3.1.2 Disinfectant pump

Disinfectant pump was the energy source for spraying disinfection system whose power was transmitted by belt drive system. Disinfectant pump output liquid medicine and made spray sprinkler work normally. Design of the disinfectant pump should comprehensively consider the forward speed, operation width, spraying flow, spraying area and other factors ${ }^{[15]}$. When the width and flow of spraying disinfection system were constant, the forward speed affected spraying flow in unit time directly, so:

$$
Q=q \cdot a
$$

where, $Q$ is the total dose of sprinkler spraying in unit time, $\mathrm{L} / \mathrm{h}$; $q$ is the dose of one single sprinkler spraying in unit time, $\mathrm{L} / \mathrm{h}$.

The whole spraying area in unit time could be expressed:

$$
W=L_{z} \cdot v_{m}
$$

where, $W$ is the whole spraying area in unit time, $\mathrm{m}^{2} ; v_{\mathrm{m}}$ is the forward speed of driving machine, $\mathrm{km} / \mathrm{h}$.

According to the actual requirements, the dose of microbial disinfectant in unit area was given by:

$$
m=\frac{M}{W_{z}}
$$

where, $m$ is the dose of microbial disinfectant in unit area, $\mathrm{L} / \mathrm{m}^{2}$; $M$ is the total dose of microbial disinfectant, $\mathrm{L} / \mathrm{m}^{2} ; W_{\mathrm{z}}$ is the total spraying area, $\mathrm{m}^{2}$.

The total dose of microbial disinfectant should meet:

$$
Q \geq W \cdot m
$$

From Equations (1)-(5)

$$
Q \geq \frac{M \cdot L_{z} \cdot v_{m}}{W_{z}}
$$

According to the agronomic requirements of mechanized rotary tillage and soil preparation technology in northeast China, the forward speed of driving machine was $v_{m}=4-6 \mathrm{~km} / \mathrm{h}$, the dose of disinfectant pump per hectare was $M=450 \mathrm{~L} / \mathrm{km}^{2}$. These parameters were substituted into the Equation (6) to calculate $Q=2878 \mathrm{~L} / \mathrm{h}$. MB345/2.5 type diaphragm pump was chosen to adjust pressure valve to control the flow in unit time, and improve the spraying adaptability.

\subsection{Rotary tillage system}

Rotary tillage system was the key part which could stir soil disinfectant into different depth soil. Configuration of cutter roller was the core of rotary tillage system, which affected the spray mixing uniformity and quality directly.

\subsubsection{Transmission methods}

Combined with the agronomic requirements and the configuration of whole machine, an improved design of rotary cultivator with a width of $1600 \mathrm{~mm}$ was selected. In order to install liquid medicine box conveniently and to improve the capacity of spraying, the main frame of rotary tiller adopted a lightweight composition design, on which fixed mount was configured symmetrically. The whole transmission methods are shown in Figure 4. The whole machine adopted biaxial central transmission that made the power transmit from power output shaft of tractor to main gearbox by universal joint. Drive shaft was fixed on the side of main gearbox making the pump work normally by belt wheel. The power was transmitted to auxiliary gearbox from the other side, and then the power was impacted on cutter shaft, and the land preparation operations were carried out. 


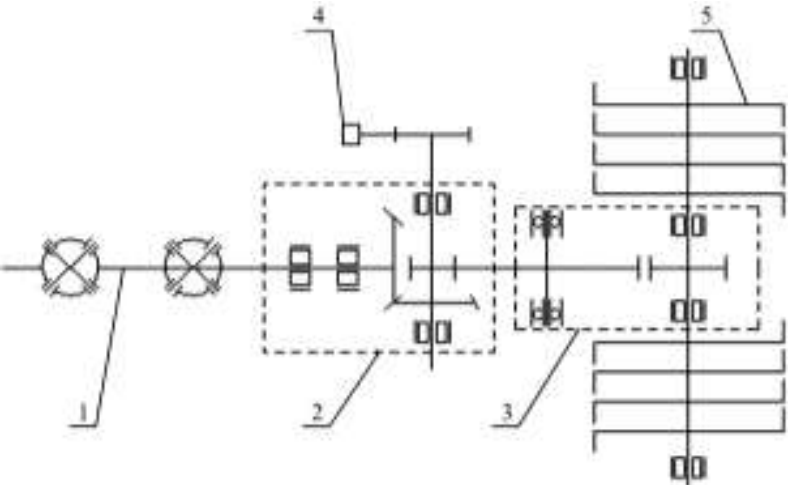

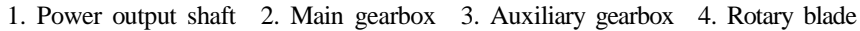
5. Disinfectant pump

Figure 4 Transmission methods of rotary tillage land preparation system

\subsubsection{Rotary tillage cutter roller}

Rotary tillage cutter roller was the key part of rotary tillage land preparation system. The design and arrangement for rotary blades affected the spray mixing uniformity of plowing, quality of crumbling soil, and power consumption. Compared with the rotating operation in forward and backward ${ }^{[16]}$, the cutter roller rotating in backward could result in blocking, as its work form of bottom-up cutting soil could throw the clod into the rear. In order to avoid blocking spray sprinklers, the cutter roller rotating in forward was adopted. IT245 type rotary blade was chosen according to Chinese national standard GB/T 5669-2008 (Rotary tiller-rotary blades and blade holders), which had two turning directions including left and right. And its turning radius was $245 \mathrm{~mm}$, operation width was $45 \mathrm{~mm}$, material was $65 \mathrm{Mn}$.

In order to improve the endurance and flexural strength of rotary blade, the hardness of the rotary tillage was HRC50-55 by quenching. In actual rotary tillage operation, the application for the whole system should decrease the forward speed of driving machine, increase the rotational speed of rotary tillage and add the quantity of rotary blades in per cutting area to improve the spray mixing uniformity between soil and disinfectant. If the forward speed of driving machine was too slow, it could result in low efficiency. If the rotational speed of rotary tillage was too fast, it could result in increasing power consumption. If the quantity of rotary blades in per cutting area is added, it could result in winding grasses and jams of mud ${ }^{[17]}$. When the soil moisture rate was $20 \%-30 \%$, the distance of cutting soil should be more than $100 \mathrm{~mm}$. When the soil moisture rate was more than $35 \%$, the distance of cutting soil should be at $60-90 \mathrm{~mm}$. The quantity of rotary blades in per cutting area was as follows:

$$
Z=\frac{60000 v_{m}}{n \cdot S}
$$

where, $n$ is the rotational speed of rotary tillage, $\mathrm{r} / \mathrm{min} ; Z$ is the quantity of rotary blades in per cutting area; $S$ is the distance of cutting soil, $\mathrm{mm}$.

Taking the requirements of soil cutting and the influences of power consumption into account, the rotational speed of rotary tillage was $n=300-600 \mathrm{r} / \mathrm{min}$, the distance of cutting soil was $S=$ $80 \mathrm{~mm}$. These parameters were substituted into the Equation (7) to calculate the quantity of rotary blades was $Z=2-4$.

The reasonable arrangement of rotary blades could improve mixing uniformity, reduce power consumption and failure rate of operation $^{[18]}$. Therefore, arrangement of rotary blades should meet the following requirements: 1) Axial installation distance and radial adjacency angle of rotary blades should be increased to avoid the interference and relieving abrasion from blades. 2) Axial installation angle for adjacent blades should be equal, and stress of cutter shaft should be uniform, vibration of the whole machine should be reduced, and the leaking should be avoided. 3) The rotating cutter of left side and right side should enter into soil alternately, and the stress of the whole machine should be balanced to ensure work normally.

Combined with the advantages and disadvantages of different arrangement and actual characteristic of configuration, the bifilar helix arrangement of blade holders was adopted, as shown in Figure 5. Cutter shaft was divided into two parts. The width of auxiliary gearbox was $82 \mathrm{~mm}$, and length of each cutter shaft was $878 \mathrm{~mm}$, and the quantity of left or right rotary blades was 25 . The phase angle of opposite blades differed $180^{\circ}$ in the same plane, and the lifting angle of adjacent blades in the same bifilar helix was $60^{\circ}$.

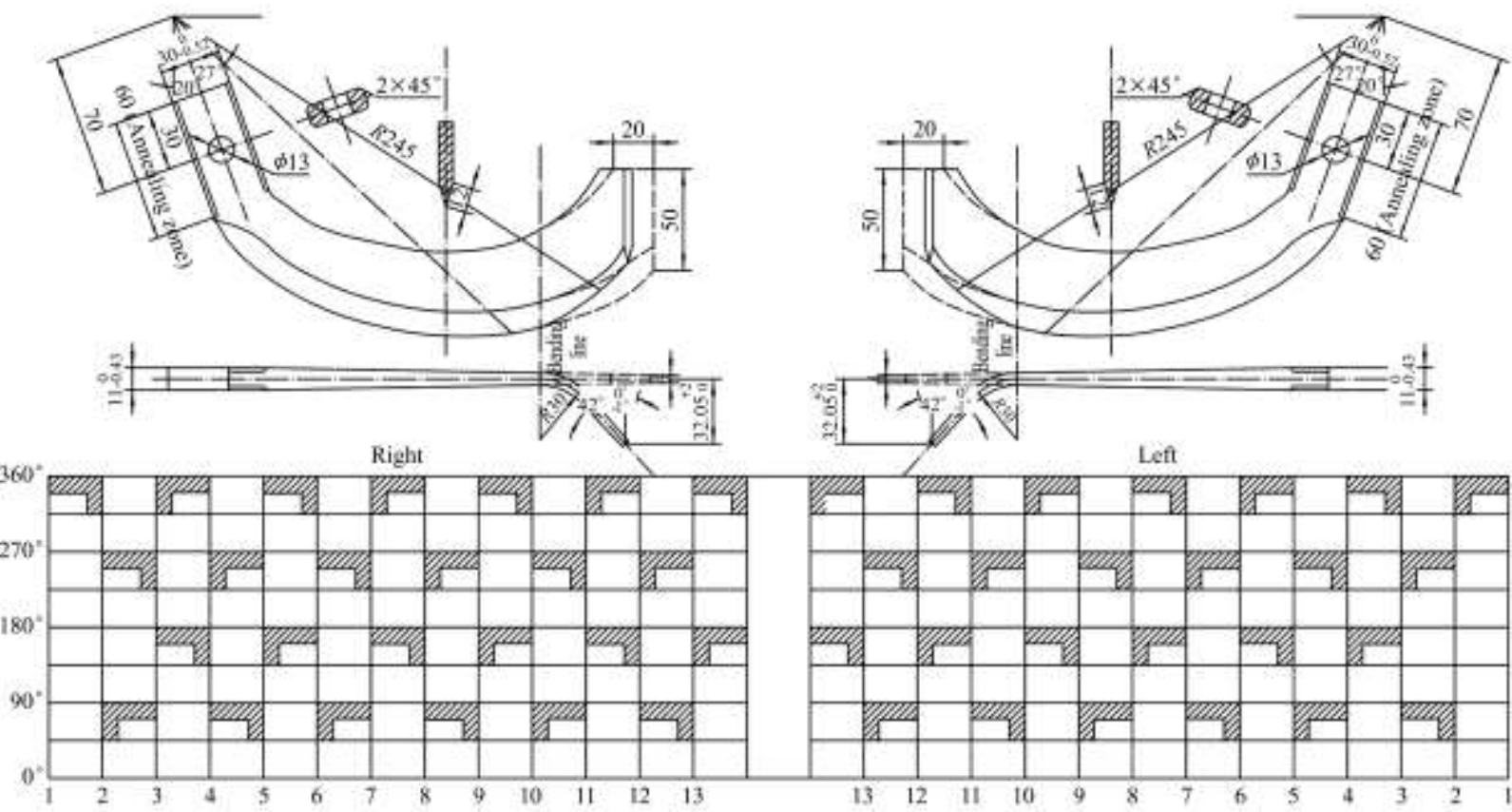

Figure 5 Arrangement form of rotary blades 


\section{Materials and methods}

\subsection{Test materials}

In order to optimize the working performance of combined disinfection machine, clarify the effects of influencing factors on performance and obtain better operation parameters, a field experiment was conducted on April 2017 at agricultural testing farm of Northeast Agricultural University in Harbin, China. The experimental field was at demonstration field of maize with an area of $1000 \mathrm{~m}^{2}$. The soil was black loam. The moisture content and compaction strength of soil were $13 \%-20 \%$ and $280-480 \mathrm{kPa}$ at $5-20 \mathrm{~cm}$ depth. The ambient temperature was $13^{\circ} \mathrm{C}$, environmental humidity was $51 \%$ and average wind speed was $1.5-2.0 \mathrm{~m} / \mathrm{s}$, all these conditions met the agronomic requirements. The spray and rotary tillage combined disinfection machine was driven by Foton Lovol 904 type tractor. A kind of environment-protection microbial disinfectant was chosen as experimental disinfectant. The actual operation is shown in Figure 6.

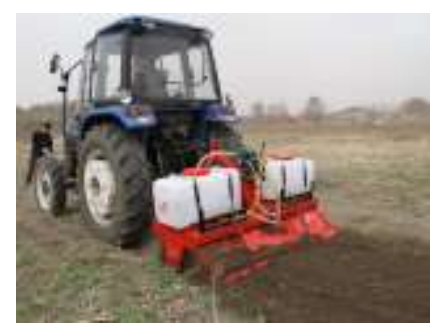

a. Experimental prototype

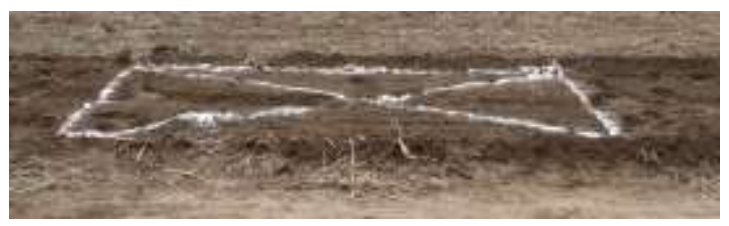

c. Experiment measurement

Figure 6 Actual operation of field experiment

\subsection{Test factors and response indexes}

According to the above theoretical analysis and actual field operations, there were many factors and interactions that could affect the quality of compound operation, such as mixing uniformity of rotary tillage and uniformity for spraying. In actual field operation, spraying flow of disinfection could be controlled by adjusting the regulator of disinfectant pump, and the quality of rotary tillage could be controlled by changing the forward speed of driving machine and rotational speed of power output shaft. Thus, the forward speed of driving machine, rotational speed of rotary tillage and working pressure for spraying were selected as the experiment factors. Combined with above theoretical analysis, requirements of actual field operation and single factor experiments, the variation ranges of three factors were determined. The factors and levels are shown in Table 2.

Table 2 Factors and levels of experiments

\begin{tabular}{cccc}
\hline \multirow{2}{*}{ Levels } & \multicolumn{3}{c}{ Factors } \\
\cline { 2 - 4 } & $\begin{array}{c}\text { Forward speed } A \\
/ \mathrm{km} \cdot \mathrm{h}^{-1}\end{array}$ & $\begin{array}{c}\text { Rotational speed } B \\
/ \mathrm{r} \cdot \mathrm{min}^{-1}\end{array}$ & $\begin{array}{c}\text { Working pressure } C \\
/ \mathrm{MPa}\end{array}$ \\
\hline 1 & 3 & 300 & 0.5 \\
2 & 4 & 400 & 1.0 \\
3 & 5 & 500 & 1.5 \\
4 & 6 & 600 & 2.0 \\
\hline
\end{tabular}

According to Chinese national standards GB/T 50085-2007 (Technical code for sprinkler engineering) and GB/T 5668-2008
(Rotary tiller), the evaluation indexes were soil spray mixing uniformity coefficient (Christiansen uniformity coefficient) and variation coefficient. In order to improve the operability and accuracy of experiments, the research adopted the test of soil moisture content for different depth instead of the mixing effects of microbes disinfectant in soil, and then the effects of mixed spraying was evaluated further. The dose of microbial disinfectant was controlled normally to make sure the mixture between soil and disinfectant is fully mixed. When the dose of microbial disinfectant was too much, the disinfectant could have side-effects and the following operation part would be affected. When the dose of microbial disinfectant was too little, the effect of disinfection is not remarkable. It was very necessary to achieve the effect of full contact between soil and disinfectant by rotary tillage. Because the relative changes of soil moisture were not obvious, the times of compound operation should be added to make it obviously, and the whole operation was made 22 times in fact. The calculation equations of indexes are as follows:

$$
\begin{gathered}
C_{u}=\left(1-\frac{\sum_{i=1}^{N}\left|\theta_{i}-\bar{\theta}\right|}{N \bar{\theta}}\right) \times 100 \% \\
C_{v}=\frac{C}{\bar{\theta}} \times 100 \% \\
\bar{\theta}=\frac{\sum_{i=1}^{N} \theta_{i}}{N}
\end{gathered}
$$

where, $C_{u}$ is the Christiansen uniformity coefficient, \%; $C_{v}$ is the variation coefficient, $\% ; N$ is the number of measurement points; $\bar{\theta}$ is the average soil moisture content, $\% ; \quad \theta_{i}$ is the soil moisture content of measurement points, $\%$; $C$ is the standard deviations of soil moisture content, $\%$.

In order to reduce the errors of experiments, the operation area was divided into promoter region, test region and stop region. The total distance of test was $200 \mathrm{~m}$, and the distance of promoter region and stop region were $20 \mathrm{~m}$, respectively. When the experimental prototype entered into the test region, the forward speed of driving machine and rotational speed of power output shaft were controlled to meet the requirements of test. The disinfection area was chosen randomly with a length of $3 \mathrm{~m}$ and a width of $2 \mathrm{~m}$, and it was arranged measurement points for soil moisture content. Measurement points were divided into five groups including four vertexes and diagonal intersection of rectangle. Soil moisture content was tested in different depth by humidity measuring instrument to analyze the uniformity, and the depth were $5 \mathrm{~cm}, 10 \mathrm{~cm}$ and $15 \mathrm{~cm}$ respectively. The soil moisture meter (with accuracy of $0.1 \%$ ) was developed by Zhejiang University.

\section{Results and discussion}

\subsection{Test results}

By evaluating the interactions among different factors, the orthogonal array $\mathrm{L}_{16}\left(4^{5}\right)$ was used to arrange the experiments ${ }^{[19-21]}$. Three repeated tests were carried out under working conditions, and the average value was taken as experimental data. The schemes and results of experiments were analyzed by Design-Expert 6.0 software, as shown in Table 3. A black column, marked as "error", was added to estimate the test error. Thus the data could be analyzed by variance analysis (ANOVA), as shown in Table 4.

When the whole machine finished the operation, average depth 
of rotary tillage measured was $17 \mathrm{~cm}$, the soil moisture content was $34 \%$ at $0-50 \mathrm{~cm}$ depth, $32 \%$ at $50-100 \mathrm{~cm}$ depth, and $36 \%$ at $100-150 \mathrm{~cm}$ depth. All effects of operation could meet the agronomic requirements. For compound operation, the larger the soil spray mixing uniformity coefficient was, the smaller the variation coefficient was, it could prove that the better mixing uniformity of soil and disinfectant was, and the better disinfectant effect was. From Table 3, the rules can be obtained in which the primary and secondary effect orders of each factor on the objective functions. The effect intensity of factors on the spray mixing uniformity coefficient was that forward speed $A>$ rotational speed $B>$ working pressure $C$, and the better factors combination was $A_{1} B_{4} C_{4}$. The effect intensity of factors on the variation coefficient was that forward speed $A>$ rotational speed $B>$ working pressure $C$, and the better factors combination was $A_{1} B_{4} C_{2}$.

Table 3 Schemes and results of experiments

\begin{tabular}{|c|c|c|c|c|c|c|}
\hline \multirow{2}{*}{\multicolumn{2}{|c|}{ No. }} & \multicolumn{3}{|c|}{ Factors } & \multicolumn{2}{|c|}{ Test evaluation indexes } \\
\hline & & Forward speed $A / \mathrm{km} \cdot \mathrm{h}^{-1}$ & Rotational speed $B / r \cdot \min ^{-1}$ & Working pressure $C / \mathrm{MPa}$ & Uniformity coefficient $C_{u} / \%$ & Variation coefficient $C_{V} / \%$ \\
\hline & 1 & $1(3)$ & $1(300)$ & $1(0.5)$ & 90.45 & 9.50 \\
\hline & 2 & 1 & $2(400)$ & $2(1.0)$ & 90.95 & 9.03 \\
\hline & 3 & 1 & $3(500)$ & $3(1.5)$ & 91.01 & 8.90 \\
\hline & 4 & 1 & $4(600)$ & $4(2.0)$ & 93.95 & 6.01 \\
\hline & 5 & $2(4)$ & 1 & 2 & 85.99 & 13.01 \\
\hline & 6 & 2 & 2 & 1 & 86.03 & 13.65 \\
\hline & 7 & 2 & 3 & 4 & 86.97 & 13.02 \\
\hline & 8 & 2 & 4 & 3 & 87.03 & 12.95 \\
\hline & 9 & $3(5)$ & 1 & 3 & 83.14 & 16.84 \\
\hline & 10 & 3 & 2 & 4 & 84.53 & 15.35 \\
\hline & 11 & 3 & 3 & 1 & 85.56 & 14.45 \\
\hline & 12 & 3 & 4 & 2 & 86.24 & 13.75 \\
\hline & 13 & $4(6)$ & 1 & 4 & 81.12 & 18.65 \\
\hline & 14 & 4 & 2 & 3 & 81.21 & 18.56 \\
\hline & 15 & 4 & 3 & 2 & 82.99 & 17.01 \\
\hline & 16 & 4 & 4 & 1 & 83.13 & 16.85 \\
\hline \multirow{5}{*}{$C_{u}$} & $k_{1}$ & 91.59 & 85.18 & 86.29 & \multirow{5}{*}{\multicolumn{2}{|c|}{$A_{1} B_{4} C_{4}$}} \\
\hline & $k_{2}$ & 86.51 & 85.68 & 86.54 & & \\
\hline & $k_{3}$ & 84.87 & 86.63 & 85.60 & & \\
\hline & $k_{4}$ & 82.11 & 87.59 & 86.64 & & \\
\hline & $R$ & 9.48 & 2.41 & 1.04 & & \\
\hline \multirow{5}{*}{$C_{v}$} & $k_{1}$ & 8.36 & 14.50 & 13.61 & \multirow{5}{*}{\multicolumn{2}{|c|}{$A_{1} B_{4} C_{2}$}} \\
\hline & $k_{2}$ & 13.16 & 14.15 & 13.20 & & \\
\hline & $k_{3}$ & 15.10 & 13.35 & 14.32 & & \\
\hline & $k_{4}$ & 17.77 & 12.39 & 13.26 & & \\
\hline & $R$ & 9.41 & 2.11 & 1.06 & & \\
\hline
\end{tabular}

Note: $A, B$ and $C$ mean coded values of forward speed, rotational speed and working pressure respectively; $k_{1}, k_{2}, k_{3}$ and $k_{4}$ mean the average values of each level respectively.

Table 4 Results of ANOVA

\begin{tabular}{|c|c|c|c|c|c|c|}
\hline Test index & Variation source & Standard deviation square & Degree of freedom & Mean square $M S$ & F value & Significance \\
\hline \multirow{3}{*}{ Uniformity coefficient $C_{u}$} & $A$ & 190.44 & 3 & 63.48 & 142.58 & $* *$ \\
\hline & $B$ & 13.66 & 3 & 4.55 & 10.23 & $*$ \\
\hline & $C$ & 2.66 & 3 & 0.89 & 3.96 & $N$ \\
\hline \multirow[b]{2}{*}{ Variation coefficient $C_{v}$} & $A$ & 189.06 & 3 & 63.02 & 103.29 & $* *$ \\
\hline & $B$ & 10.56 & 3 & 3.52 & 5.77 & $N$ \\
\hline
\end{tabular}

Note: ** means significance; * means relative significance; $N$ means no significance.

According to the results of ANOVA and range analysis ${ }^{[22]}$, for the working performance, the forward speed had obvious significance on uniformity coefficient and variation coefficient, rotational speed had significance on uniformity coefficient and working pressure had less significance on uniformity coefficient and variation coefficient. In actual field operation, increasing the working pressure for spraying can improve uniformity coefficient. The test showed that, the working pressure had less influence on uniformity coefficient, since the working pressure mainly controlled the quantity of flow.

The rule should be followed that the larger uniformity coefficient and the smaller variation coefficient, so that the better operation parameters of combined disinfection machine would be obtained. The optimum combination of parameters was determined as $A_{1} B_{4} C_{4}$, from which the uniformity coefficient was $93.95 \%$ and the variation coefficient was $6.01 \%$ under the 
condition that the forward speed was $3 \mathrm{~km} / \mathrm{h}$, rotational speed was $2000 \mathrm{r} / \mathrm{min}$ and working pressure was $2.0 \mathrm{MPa}$.

\subsection{Discussion}

Through improving the relative position of the sprinklers, changing the working order of spraying and rotary tillage operations, the new designed machine could achieve spraying during plowing, before plowing and after plowing, which had a strong applicability with simple structure and environmental friendly for soil disinfection. Earlier research could prove that operation effects of spraying before plowing was better than the others ${ }^{[23]}$. When the spray sprinklers were fixed in the front of main front frame, it could reduce the blocking problem. When the spray sprinklers were fixed on the covering shell, although it could achieve spraying while plowing in theory, it could block the spray sprinklers. When the spray sprinklers were fixed on the main rear frame, it could spray disinfection after plowing to cause the disinfectant sprayed on the soil surface inadequately. So the machine should be designed to achieve spraying while plowing, which could spray the disinfectant into the $3 \mathrm{D}$ plane cracked to meet the disinfection well.

\section{Conclusions}

1) A spray and rotary tillage combined disinfection machine for soil was designed and configured. The machine could achieve compound operation to meet the agronomic requirements of disinfection and plowing, and it was designed simply, compactly, which had strong applicability

2) The orthogonal experiment was conducted to verify the effects of these influencing factors on the working performance. The results showed that, the factors affacting the working performance in a descending order were as forward speed $A$, rotational speed $B$, working pressure $C$. The soil spray mixing uniformity coefficient was $93.95 \%$ and the variation coefficient was $6.01 \%$ under the condition that the forward speed was $3 \mathrm{~km} / \mathrm{h}$, rotational speed was $2000 \mathrm{r} / \mathrm{min}$ and working pressure was 2.0 MPa.

The research of spray and rotary tillage combined disinfection machine for soil can solve disinfection and plowing compound operations, which can control the plant diseases and insect pests, has great significance to develop sustainable ecological agriculture and provide the technology supports for mechanical efficient compound cultivation.

\section{Acknowledgements}

The authors acknowledge the financial support provided by the National Industry System of Rice Technology of China (CARS-01-44) and Heilongiiang Modern Industrial Technology Collaborative Innovation System.

\section{[References]}

[1] Yang Y S, Wu C C, Feng C P. The research status of precision agricultural in Japan. Transactions of the CSAM, 2001; 32(2): 107-110. (in Chinese)

[2] Wu F Z, Liu D, Wang D K, Luan F S, Wang W, Liu Y Y. Effect of continuous vegetable cropping in plastic greenhouse on the soil physical and chemical properties. China Vegetables, 1998; 4(7): 7-10. (in Chinese)

[3] Jia H L, Wang W J, Wang W P, Zheng J, Wang Q, Zhuang J. Application of anti-adhesion structure based on earthworm motion characteristics. Soil \& Tillage Research, 2018; 178: 159-166.

[4] Darko R O, Yuan S Q, Liu J P, Yan H F, Zhu X Y. Overview of advances in improving uniformity and water use efficiency of sprinkler irrigation. Int J Agri \& Biol Eng, 2017; 10(2): 1-15.

[5] Gao Z C, Li L J, Yang H J, Zhu Q, Zhou Y, Min S H. Design and experiment of pros spiral lime spreading machine. Transactions of the CSAE, 2015; 31(10): 43-50. (in Chinese)

[6] Wu X F, Zhou Y, Chen J, Qian L H. Effect of different soil disinfectant on soil temperature and soil nutrient in sunlight greenhouse. Journal of Anhui Agricultural, 2015; 43(11): 85-87. (in Chinese)

[7] Zhou F B, Hu S Y, Liu Y K, Liu C, Xia T Q. CFD-DEM simulation of the pneumatic conveying of fine particles through a horizontal slit. Particuology, 2014; 16: 196-205.

[8] St Jack D, Hesterman D C, Guzzomi A L. Precision metering of Santalum spicatum (Australian Sandalwood) seed. Biosystems Engineering, 2013; 115(2): 171-183.

[9] Lei X L, Liao Y T, Zhang Q S, Wang L, Liao Q X. Numerical simulation of seed motion characteristics of distribution head for rapeseed and wheat. Computers and Electronics in Agriculture, 2018; 150: 92-109.

[10] Zhao Y, Chen X G, Wen H J, Zheng X, Niu Q, Kang J M. Research status and prospect of control technology for residual plastic film pollution in farmland. Transactions of the CSAM, 2017; 48(6): 1-14. (in Chinese)

[11] Sarker K K, Xu C L, Wang X Y, Li M J, Li L H, Liu G M. Band tillage with fertilizer application for unpuddled transplanting rice in northeast of china. Int J Agri \& Biol Eng, 2016; 9(4): 73-83.

[12] Wang J W, Tang H, Wang J F, Lin N N, Huang H N, Zhao Y. Design and experiment on 1DSZ-350 type hanging unilateral rotary tillage compacting ridger for paddy field. Transactions of the CSAE, 2017; 33(1): 25-37. (in Chinese)

[13] Frabetii D R, Resende R C, Queironz D M, Fernmades H C, Solza C M. Development and evaluation performance of a punch planter for planter for direct sowing of corn. Revista Brasileira de Engenharia Agricola E Ambiental, 2011; 15(2): 199-204.

[14] Song W, Zhou H P, Zhang H C, Yu J, Dai Z H. Performance analysis on rotating-cage spraying atomizer of biological pesticide. Journal of Nanjing Forestry University, 2012; 36(5): 134.

[15] Zang Y, Gu X Y, Zhou Z Y, Luo X W, Zang Y, Qi X Y, et al. Review of tensairity and its applications in agricultural aviation. Int J Agri \& Biol Eng, 2016; 9(3): 1-14.

[16] Ding W M, Wang Y H, Peng S Z. Comparison on performances of up-cut and down-cut rotary tillage. Journal of Nanjing Agricultural University, 2003; 26(3): 106-109.

[17] Rajaiah P, Mani I, Kumar A, Lande S D, Singh A K, Vergese C. Development and evaluation of electronically controlled precision seed-metering device for direct-seeded paddy planter. Indian Journal of Agricultural Sciences, 2016; 86(5): 598-604.

[18] Londo J P, Kovaleski A P. Characterization of wild North American grapevine cold hardiness using differential thermal analysis. American Journal of Enology and Viticulture, 2017; 68(2): 203-212.

[19] Liu T H, Ehsani R, Toudeshki M, Zou X J, Wang H J. Experimental study of vibrational acceleration spread and comparison using three citrus canopy shaker shaking tines. Shock \& Vibration, 2017; 1: 1-9.

[20] Manjula E V P J, Ariyaratne W K H, Ratnayake C, Melaaen M C. A review of CFD modeling studies on pneumatic conveying and challenges in modeling offshore drill cutting transport. Powder Technology, 2017; 305: 782-793.

[21] Wang J W, Tang H, Wang J F, Shen H G, Feng X, Huang H N. Analysis and experiment of guiding and dropping migratory mechanism on pickup finger precision seed metering device for corn. Transactions of the CSAM, 2017; 48(1): 29-37, 46. (in Chinese)

[22] Johansen C, Haque M E, Bell R W, Thierfelder C, Esdaile R J. Conservation agriculture for small holder rainfed farming: Opportunities and constraints of new mechanized seeding systems. Field Crops Research, 2012; 132: 18-32.

[23] Zhu X Y, Yuan S Q, Liu J P. Effect of sprinkler head geometrical parameters on hydraulic performance of fluidic sprinkler. Journal of the Irrigation and Drainage, 2012; 138(11): 1019-1026. 